\title{
Well-differentiated liposarcoma
}

INSERM

\section{Source}

INSERM. (1999). Orphanet: an online rare disease and orphan drug data base. Well-

differentiated liposarcoma. ORPHA:99971

Well-differentiated liposarcoma (WDLS), the most common type of liposarcoma (LS; see this term), is a slow growing, painless tumor usually located in the retroperitoneum or the limbs. It is composed of proliferating mature adipocytes. 